\title{
Comparison of Different Liquid and Semisolid Vehicles Selected for Oral Administration of Pellets and Minitablets with Diazepam: In Vitro Investigation
}

\author{
Hanna Kotlowska, ${ }^{1}$ Marta Szymanska, ${ }^{2}$ and Malgorzata Sznitowska ${ }^{1,3}$
}

Received 9 May 2020; accepted 11 July 2020; published online 31 July 2020

\begin{abstract}
The acceptability and palatability of a dosage form are extremely important to improve patient compliance. Mixing oral solid dosage forms with food carriers is often necessary to ease swallowing and provide the taste-masking effect. The present research investigated how a liquid or semisolid carrier influences the disintegration time and drug dissolution rate of pellets and minitablets with diazepam. The disintegration of pellets and minitablets in liquid carriers (water, milk and apple juice) was determined using a texture analyser. Dissolution tests were performed for the dosage forms dispersed in gel vehicles $(2 \%$ carmellose and $0.5 \%$ carbomer gels) or applesauce. The disintegration of minitablets in water and apple juice was fast ( $1 \mathrm{~min})$, but it slowed to 3 and $5 \mathrm{~min}$ in milk and gel vehicles, respectively. The pellets disintegrated in liquid carriers within $3 \mathrm{~min}$. The drug dissolution rate in $0.1 \mathrm{M} \mathrm{HCl}$ depended on the gel viscosity in this medium. The preserved high viscosity of a carmellose gel inhibited the dissolution of diazepam. On the other hand, the viscosity of the carbomer gel decreased rapidly, and in effect, the dissolution rate of diazepam from the incorporated pellets or minitablets was comparable to the dissolution from loose pellets or minitablets.
\end{abstract}

KEY WORDS: pellets; minitablets; sprinkle; disintegration; dissolution.

\section{INTRODUCTION}

Swallowing difficulties (dysphagia) are becoming more common. Approximately $70-90 \%$ of the elderly and $25-45 \%$ of children experience swallowing problems (1). The lack of commercially available, age-appropriate medicinal products forces patients and caregivers to manipulate the dosage form, including breaking or crushing the tablets or mixing them with food or drink. All of these actions may reduce clinical efficacy or increase the risk of adverse reactions when the chemical and physical stability or bioavailability is affected (2). Sprinkles are a new medicinal product of multiparticulate solid oral dosage forms dedicated for mixing with soft food or liquids (3).

Sprinkles occur as beads (e.g., granules, pellets, or minitablets) packed in capsules or sachets that are designed to be removed and mixed with a liquid or a soft food before administration, to improve swallowability. The carrier supports the taste-masking properties, which significantly

\footnotetext{
${ }^{1}$ Department of Pharmaceutical Technology, Medical University of Gdansk, Al. Hallera 107, 80-416, Gdansk, Poland.

${ }^{2}$ Student Chapter of the ISPE, Department of Pharmaceutical Technology, Medical University of Gdansk, Gdańsk, Poland.

${ }^{3}$ To whom correspondence should be addressed. (e-mail: msznito@gumed.edu.pl)
}

improve patient compliance. Several studies showed that sprinkles are more acceptable by children and their caregivers than liquid dosage forms (4-6). Sprinkle formulations are gaining more popularity because they are presented as singledose, preservative-free and taste-masked products (7).

The beads may be coated to mask the unpleasant taste of the active substance (8). The coating of multiparticulate formulations also provides the opportunity to modify the release kinetics of the active substance. There are enteric and sustained release products in which polymers are soluble in $\mathrm{pH}$ above 5.5 or insoluble but permeable for water, respectively. The manufacturing of modified-release dosage forms that are acceptable for children is especially important due to the small number of such products available on the market (9).

According to the FDA (Food and Drug Administration) guideline from 2012, the maximum size of beads formulated as sprinkles is up to $2.8 \mathrm{~mm}$, which is the size that does not stimulate the urge to chew (10). It is especially important in cases of the modified-release multiparticulates, where unintended chewing may change the pharmacokinetics of the active pharmaceutical ingredient (API) (11). The pilot clinical study of Kluk et al. (12) demonstrated that preschool children easily swallowed several minitablets $(2$ and $3 \mathrm{~mm})$ when they were sprinkled on a fruity jelly. However, the authors emphasized the relatively high frequency of chewing (even 
$23 \%$ ) because children from an early age are taught to bite or chew food to eliminate the risk of choking.

The recently published FDA draft guidance (13) proposes in vitro methods for testing the sprinkle drug product and the vehicle mixture. It is important to standardize a methodology that supports the selection of an appropriate vehicle. The vehicle choice was often based on the acceptable taste and texture rather than on physiochemical characteristics, which may affect the oral bioavailability or stability of the API (14). The need to demonstrate that the drug product quality is maintained when it is mixed with the vehicle is highlighted in the guideline. A 2-h stability test of drug product-vehicle mixture is recommended, and some general recommendations for the dissolution testing are also provided. The drug release profile from the original product and the product-vehicle mixture as determined with pharmacopoeial tests should be consistent. Any significant differences in vitro may indicate a risk of change in bioavailability; however, the in vitro testing cannot replace the in vivo foodeffect studies, especially for modified-release products (15).

The most commonly used liquid carriers for sprinkling are apple juice or breast and infant formula milk, and common soft foods are yogurt, pudding, fruit and vegetablebased baby food, especially applesauce. Due to the natural origin of these products, any changes in the composition due to regional or climate conditions cannot be excluded. Therefore, standard suspending vehicles appeared on the market. An example is Ora ${ }^{\circledR}$-Sweet, which is a suspending, flavouring and sweetening liquid vehicle. However, it is primarily used in pharmaceutical compounding as a vehicle in oral suspensions (16). A commercially available lubricating gel with carrageen and maltodextrin (Gloup Original) is used to facilitate the swallowing of solid oral drugs in children from 2 years of age. It is described as safe with no effect on the dissolution rate of paracetamol from tablets (17). Kluk and Sznitowska (18) defined the physical properties of a semisolid gel that is appropriate for the administration of minitablets and pellets. Viscosity, texture/ductility, spilling risk from a spoon under shaking and the disintegration time of minitablets in the gels were examined. The tests were designed to imitate the real conditions that occur during the administration of a medicine. The best application properties were demonstrated for medium viscosity gels, such as $1 \%$ or $1.5 \%$ carmellose sodium gels and $0.25 \%$ or $0.5 \%$ carbomer gels.

In the present study, immediate release pellets and minitablets with diazepam were formulated. Diazepam is a benzodiazepine derivative anxiolytic drug. It is a lipophilic compound $(\log \mathrm{P}=2.8)$ with limited solubility in water, less than $50 \mu \mathrm{g} / \mathrm{ml}$ (19). Diazepam is more often prescribed for elderly patients, and it is available on the market as tablets in strengths of $2 \mathrm{mg}$ and $5 \mathrm{mg}$. The drug is also used in children for premedication, but the dosage accuracy of $0.3 \mathrm{mg} / \mathrm{kg}$ body weight is required in this case (20). The oral solution is available for children from 6 months; however, it contains alcohol as co-solvent and the stability after the first opening is limited (21). Solid oral multiparticulate dosage forms (pellets and minitablets) exhibit better stability and allow flexible dose adjustments in children of different ages. The study tested the in vitro disintegration in liquid and semisolid carriers, and the dissolution rates for the dosage forms dispersed in the hydrophilic gels and applesauce were determined. The study examined any possible influence of the carrier on the performance of solid dosage forms in in vitro conditions and justified the methodology of these tests in sprinkle dosage form development. An attempt to propose a suitable gel vehicle was also undertaken.

\section{MATERIALS AND METHODS}

\section{Materials}

Diazepam was kindly donated by Polfa Tarchomin (Warsaw, Poland). The pellets were composed of microcrystalline cellulose (Vivapur PH101, JRS Pharma, Rosenberg, Germany) and lactose monohydrate (Sorbolac 400, Meggle, Wasserburg, Germany). The minitablets additionally contained croscarmellose sodium (Ac-di-sol, FMC BioPolymer, Newark, USA) as a superdisintegrant, sodium stearyl fumarate (Pruv, JRS Pharma, Rosenberg, Germany) as a lubricant and hypromellose (Pharmacoat 606, Shin-Etsu Chemical, Tokyo, Japan) as a binder. Carmellose (CMC) - high viscosity carboxymethylcellulose sodium (Sigma-Aldrich, Steinheim, Germany; viscosity of a $2.0 \%$ aqueous solution $5000 \mathrm{mPas}$ ) and carbomer (PAA) - and Carbopol 974P NF (Lubrizol, Brussels, Belgium; viscosity of a $0.5 \%$ aqueous solution $8000 \mathrm{mPas}$ ) were used to prepare gel vehicles for pellets and minitablets. Applesauce (Gerber, Nestle, Poland) was used as a soft food vehicle. Milk with $3.2 \%$ fat (Laciate, Mlekpol, Poland) and apple juice (Tymbark, Maspex, Poland) were used as liquid carriers.

\section{Methods}

\section{Production of Pellets}

Pellets with diazepam were produced using an extrusion and spheronization technique. In the first step, diazepam $(0.5 \% \mathrm{w} / \mathrm{w})$ was mixed with diluents, microcrystalline cellulose $(19.75 \% \mathrm{w} / \mathrm{w})$ and lactose monohydrate $(79.75 \% \mathrm{w} / \mathrm{w})$, and the dry mixture was wet with water $(40 \% \mathrm{w} / \mathrm{w})$. The wet mass was extruded using a Caleva Extruder 25 (Caleva, Dorset, UK), and the extrudate was spheronized in a Caleva 120 spheronizer (Caleva, Dorset, UK) for $8 \mathrm{~min}$ with rotation speed of $1500 \mathrm{rpm}$. These parameters were chosen in a preliminary study to ensure the best sphericity and size uniformity of pellets. The wet pellets were dried at $50^{\circ} \mathrm{C}$ and screened to collect units with sizes of 1-1.25 mm for further studies.

The pellets' sphericity was determined by calculating the ratio of orthogonal dimensions of pellets from stereomicroscopic pictures (Opta-Tech, Warsaw, Poland). From the captured image for 10 pellets, the longest axis was determined as the length (1), and the line perpendicular to the midpoint of the longest axis was the width (w). The ratio w/l was calculated. The ideal sphericity was a result of 1.0.

\section{Production of Minitablets}

The minitablets contained $0.5 \%(\mathrm{w} / \mathrm{w})$ of diazepam and the following excipients: microcrystalline cellulose $(56.1 \%$ $\mathrm{w} / \mathrm{w})$, lactose monohydrate $(37.4 \% \mathrm{w} / \mathrm{w})$ and croscarmellose 
sodium $(2.0 \% \mathrm{w} / \mathrm{w})$. The mixture was granulated with a $2 \%$ (w/w) solution of hypromellose using a high-shear wet granulation method. After granulation and drying at $50^{\circ} \mathrm{C}$, a lubricant (sodium stearyl fumarate; $3 \% \mathrm{w} / \mathrm{w}$ ) was added. The biconvex minitablets with a diameter of $2.5 \mathrm{~mm}$ and weight of $12 \mathrm{mg}$ were prepared at a compression pressure of $250 \mathrm{MPa}$ $(1.2 \mathrm{kN})$ using a rotary tablet press (RTP-D8, Erweka, Germany) equipped with single punches.

\section{Mechanical Strength of Pellets and Minitablets}

The friability test was performed in an oscillating apparatus Model EGF-1 (Electrolab, Mumbai, India). Samples of $10 \mathrm{~g}$ were tested for $2 \mathrm{~min}$ with 140 oscillations/min and afterwards were screened using a $1.0-\mathrm{mm}$ sieve. Friability was calculated as the percent of the sample weight loss.

The crushing strength test was performed using the texture analyser TA.XT plus (Stable Micro Systems, Surrey, UK). The force needed to crush a single pellet or minitablet was measured using a stainless cylinder probe. The results for 20 units are presented as a mean value and standard deviation.

\section{Disintegration of Pellets and Minitablets}

The disintegration time was determined using a texture analyser equipped with a disintegration rig (Stable Micro Systems, Surrey, UK). A single pellet or minitablet $(n=10)$ was attached to the probe using a double-sided tape, and $4 \mathrm{ml}$ of a liquid (water, milk and apple juice) was placed in a vessel with a specially perforated platform inside (Fig. 1a). The probe was brought down towards the immersed platform, and a constant $0.1 \mathrm{~N}$ load was exerted on the sample. The test started when the probe came into contact with the tested bead and lasted until the immersed platform surface was reached. The displacement of the probe was measured, and the distance versus time was plotted on a graph (Fig. 1b). The time when the displacement of the probe was not further observed corresponded to the complete disintegration of the sample (22).

Disintegration in 2.0\% CMC and $0.5 \%$ PAA gels was also tested. Six pellets or six minitablets were immersed in $4.5 \mathrm{~g}$ of a gel on a glass Petri dish (57 $\mathrm{mm}$ diameter). The test was performed at room temperature, and the times until the dry cores of a pellet or minitablet were no longer observed were measured (checked every $30 \mathrm{~s}$ with a spatula).

\section{Preparation of Gel Vehicles}

Oral gels were prepared with two different polymers, carmellose sodium $(2.0 \% \mathrm{CMC} \mathrm{w} / \mathrm{w})$ and carbomer $(0.5 \%$ PAA w/w), via dispersion of the polymer in water. PAA was dispersed at room temperature, and $\mathrm{CMC}$ required a temperature of $60^{\circ} \mathrm{C}$ for dispersion. To obtain the proper viscosity, the PAA gels were neutralized (to $\mathrm{pH} 7.0$ ) with an aqueous $\mathrm{NaOH}$ solution. The gels were stored for at least $24 \mathrm{~h}$ at $4^{\circ} \mathrm{C}$ and were used as vehicles after equilibration to room temperature.

\section{In Vitro Dissolution Tests}

Dissolution tests were performed in a basket (100 rpm) and paddle $(75 \mathrm{rpm})$ apparatus with $500 \mathrm{ml}$ of $0.1 \mathrm{M} \mathrm{HCl}$ as a dissolution medium (Pharma Test, Germany). Pellets or minitablets ( $1 \mathrm{~g}$ containing $5 \mathrm{mg}$ of diazepam) were placed in a basket or vessel as loose items or dispersed in $4.5 \mathrm{~g}$ of a vehicle: $0.5 \%$ PAA, $2.0 \%$ CMC gels or applesauce. The samples were collected after $1 \mathrm{~min}, 3 \mathrm{~min}, 5 \mathrm{~min}, 10 \mathrm{~min}$ and $30 \mathrm{~min}$ and immediately analysed. Drug content $(n=6)$ was measured using the HPLC method (LC-2030C 3D, Shimadzu, Kyoto, Japan). A mixture of acetonitrile, methanol and $1.0 \%$ $(\mathrm{w} / \mathrm{w})$ phosphate buffer $(\mathrm{pH} 3.0)$ in the ratio of 18:58:24 (v/v/ v) was used as a mobile phase with a flow rate of $1.0 \mathrm{ml} / \mathrm{min}$. Chromatographic separation was performed on a LiChrosphere reversed-phase C-18 column $(125 \times 4 \mathrm{~mm})$ with a $5-\mu \mathrm{m}$ particle size (Merck, Darmstadt, Germany). The column temperature was $25^{\circ} \mathrm{C}$, and the sample volume was $20 \mu \mathrm{l}$. The UV detector was set at $232 \mathrm{~nm}$, and the retention time of diazepam was $2.7 \mathrm{~min}$.

\section{RESULTS AND DISCUSSION}

The sieve analysis demonstrated that all prepared pellets were in the size range of $0.8-1.4 \mathrm{~mm}$, with the main fraction $(60 \%)$ in the range of $1.0-1.25-\mathrm{mmE}$, and this fraction, with good size uniformity, was selected for further studies. Moreover, good sphericity was demonstrated in microscopic pictures (Fig. 2), and high sphericity index 0.98 was calculated. The minitablets met the European Pharmacopoeia (9th edition) requirements for mass uniformity with an average mass of $12.1 \mathrm{mg}$ and the maximum percentage deviation from mean value of $2.9 \%$. The obtained dosage forms were characterized by good mechanical strength, which is required for packing into capsules or sachets. The friability was below $0.4 \%$, and the hardness was $12.4 \mathrm{~N}( \pm 1.4 \mathrm{~N})$ and $15.5 \mathrm{~N}( \pm$ $0.89 \mathrm{~N}$ ) for pellets and minitablets, respectively.

In comparison with liquid formulations, solid oral dosage forms, even if uncoated, have significant potential to reduce the unpleasant taste of the active substance, on condition that they are not disintegrated or dissolved before swallowing. To assess the maintenance of the taste-masking properties after mixing with small volumes of liquid or semisolid vehicles, the disintegration test was performed. The standard pharmacopoeial disintegration test was inapplicable because of the small size of the prepared dosage forms and difficulties with the determination of the test endpoint. An alternative test with a texture analyser equipped with a disintegration rig was used. This test allowed for better detection of disintegration time. The small volume of liquid used in the test $(4 \mathrm{ml})$ was also similar to the amount of vehicle used to disperse the sprinkle formulation in a spoon. The constant force applied to the sample also mimicked the tongue pressure that induces disintegration in vivo. This aspect should be considered, especially in patients with swallowing difficulties. Water, apple juice and milk were chosen as frequently used liquid vehicles which can facilitate the dosage form administration. They have different composition and properties, for instance $\mathrm{pH}$ value (16). The test was determined to show if these differences may affect the disintegration time of particles. 


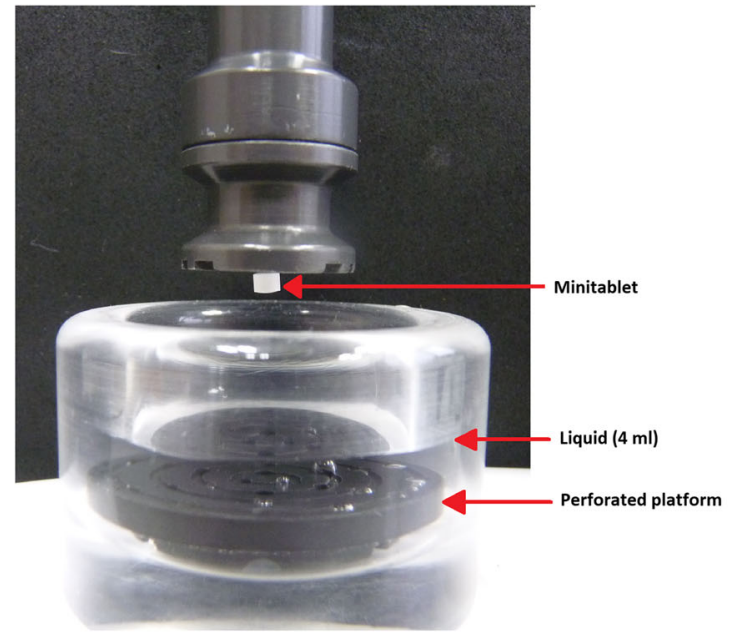

a

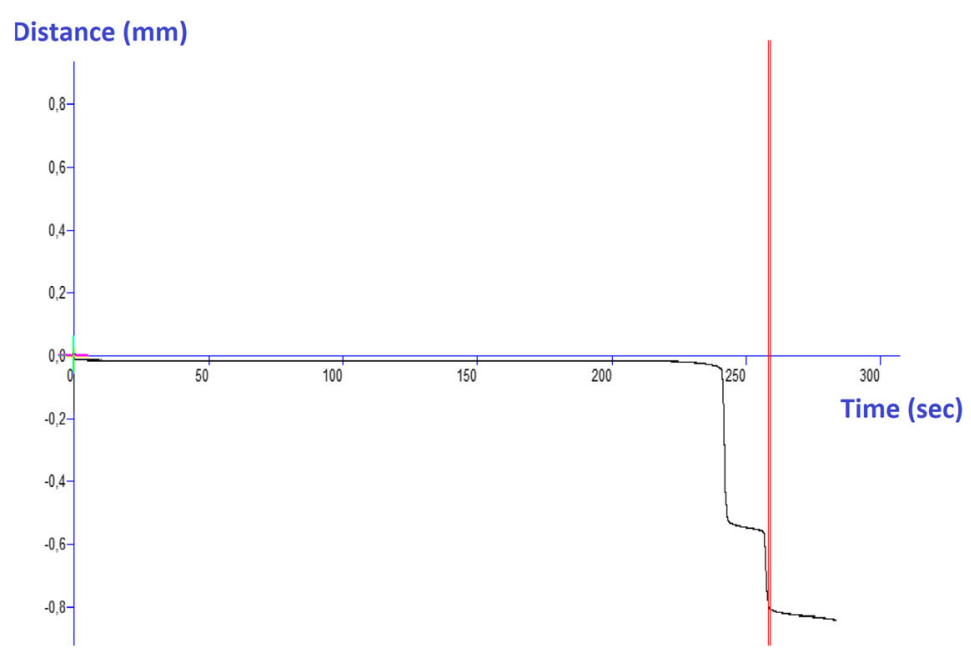

b

Fig. 1. Overview of disintegration measurement using texture analyser disintegration rig: a the probe with attached minitablet before the test and $\mathbf{b}$ typical displacement time profile

The tests performed in water showed that the pellets disintegrated within $3 \mathrm{~min}$ and minitablets disintegrated within approximately $1 \mathrm{~min}$ (Table I). Similar results were obtained in the tests performed in apple juice, but the disintegration time in milk was delayed to approximately $4 \mathrm{~min}$ for pellets and minitablets. This can be most probably related to the fat present in milk, reducing the access of water to the particle core. Larger deviations in the results were observed for pellets, which may be explained by the unstable position of the pellet under the probe due to its spherical shape, and even small changes in the measured distance resulted in large RSD (relative standard deviation) values for such small objects. However, this fast and simple test clearly showed how the type of vehicle used to disperse the sprinkles influenced the disintegration time of the investigated beads. In case of rapidly releasing formulations (within $15 \mathrm{~min}$ or less), the disintegration test can be used instead of dissolution testing, and the test can be more discriminating in the early development stages (23).

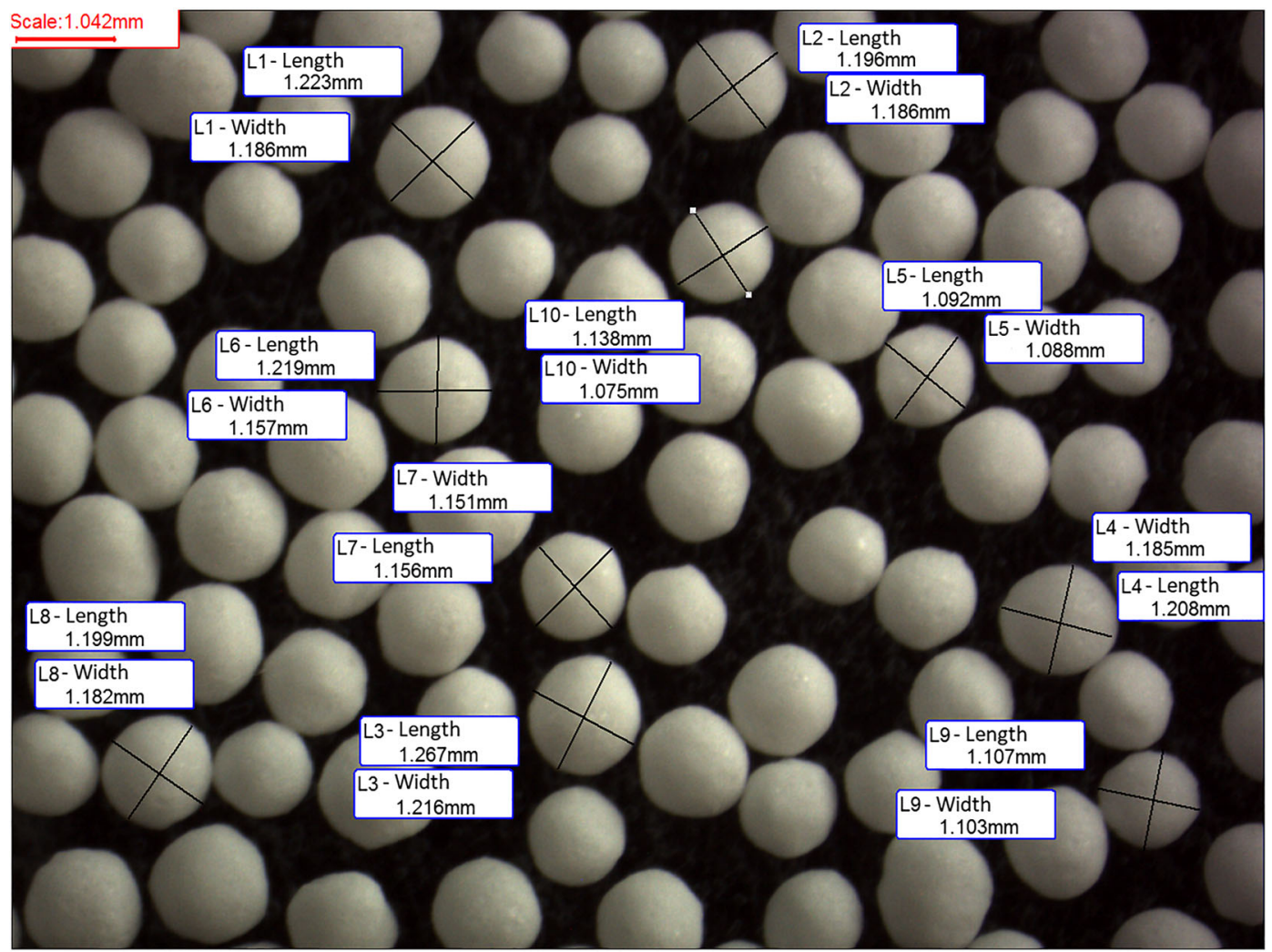

Fig. 2. Stereoscopic microscope image of pellets with the dimensions for calculation the sphericity 
Table I. Disintegration Time of Pellets and Minitablets in Liquid Carriers as Measured Using a Texture Analyser $(n=10)$

\begin{tabular}{|c|c|c|c|c|c|c|}
\hline & \multicolumn{2}{|l|}{ Water } & \multicolumn{2}{|l|}{ Milk } & \multicolumn{2}{|l|}{ Apple juice } \\
\hline & Mean $[\mathrm{min} / \mathrm{sec}]$ & RSD [\%] & Mean $[\mathrm{min} / \mathrm{sec}]$ & RSD [\%] & Mean $[\mathrm{min} / \mathrm{sec}]$ & RSD [\%] \\
\hline Pellets & $2: 56$ & 35.6 & $4: 27$ & 38.0 & $3: 11$ & 35.9 \\
\hline Minitablets & $0: 59$ & 16.4 & 4:07 & 9.8 & 1:07 & 25.5 \\
\hline
\end{tabular}

The prepared dosage forms disintegrated very fast in liquids. Therefore, in the next step, semisolid vehicles were tested as a potential aid for the administration of pellets and minitablets. CMC and PAA gels with viscosity in the range of 5000-10,000 mPas showed the best application properties (ductility and texture) for dispersing multiparticulate dosage forms (18). Additionally, good palatability may be provided because of the taste-masking properties of the gels and lubrication of the particles, which impact the mouthfeel (24). Based on these results, disintegration in $2.0 \% \mathrm{CMC}$ and $0.5 \%$ PAA gels was tested. The gels were characterized by viscosities (measured at the shear rate $10 \mathrm{~s}^{-1}$ ) of $5000 \mathrm{mPas}$ and $8000 \mathrm{mPas}$, respectively.

An attempt to use the texture analyser equipped with a disintegration rig to determine the disintegration of the units in the presence of the viscous semisolid carriers was not successful. The applied force of $0.1 \mathrm{~N}$ was too small to penetrate the gel surface. Modification of the maintained force up to $1 \mathrm{~N}$ allowed the probe to penetrate the gel, but simultaneously caused evident compression of the particles which resulted in a falsely accelerated disintegration. Therefore, the disintegration of the particles in semisolid vehicles was performed on a Petri dish. This static test simply presented how the drug product mixed with the carrier acted on a spoon. The pellets and minitablets in PAA gel and CMC gel disintegrated within $4 \mathrm{~min}$ and $5 \mathrm{~min}$, respectively. This time is sufficient to prepare the dosage form for administration without premature disintegration. On the other hand, it was important to assess the disintegration time of particles in semisolid vehicles to assess the effect of this process on the drug release profiles.

As recommended in the recently published Guidance for Industry (13), dissolution tests were performed in a basket and paddle apparatus (Fig. 3). Hydrochloric acid (0.1 M) was chosen as the dissolution medium because the in vivo acidic environment of the stomach is where non-modified-release oral dosage forms must disintegrate, and the API starts to dissolve. The original loose products were tested at first. In the next steps, the pellets and minitablets were mixed with the selected vehicles on a spoon before placement in the basket or vessel. Initially, the basket apparatus was the firstchoice instrument because it was easier to introduce the sample to the basket and afterwards to install it to the apparatus assembly.

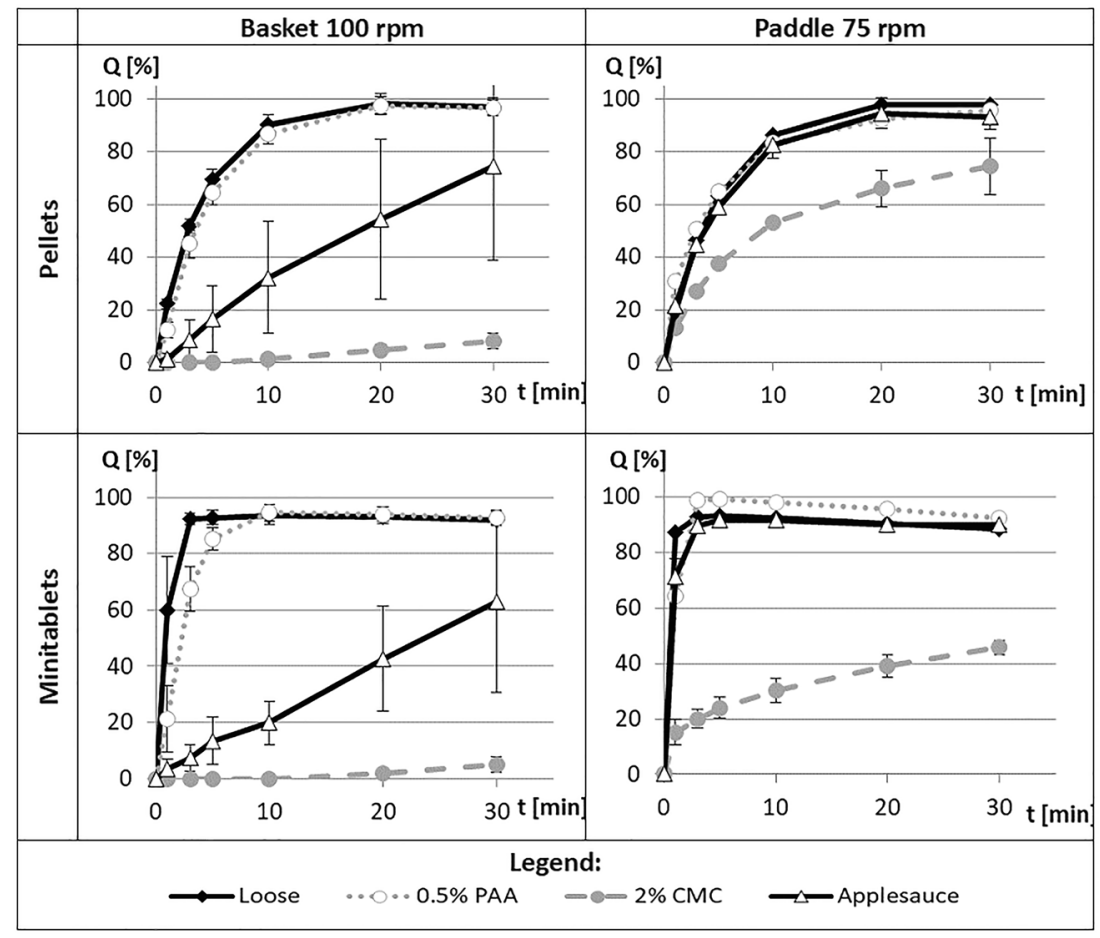

Fig. 3. Dissolution profiles of diazepam from pellets and minitablets in a basket or paddle apparatus placed loose or dispersed in a vehicle: carbomer gel (PAA), carmellose sodium gel (CMC) or applesauce 
Due to the presence of a disintegrating agent in the formulation (croscarmellose sodium), the loose minitablets showed an immediate dissolution of diazepam within 1-3 min, but diazepam from pellets dissolved slightly slower, with greater than $80 \%$ released within $10 \mathrm{~min}$. The dissolution rate of diazepam from specific dosage forms (pellets or minitablets) was similar, regardless of the type of dissolution apparatus, paddle or basket.

In the basket apparatus, similar dissolution rates were observed for the original products and beads dispersed in a carbomer gel $(0.5 \%$ PAA). In contrast, pellets and minitablets dispersed in a carmellose gel (2.0\% CMC) exhibited very slow diazepam release of only $10 \%$ during $30 \mathrm{~min}$. It was clearly visible that within the first $60 \mathrm{~s}$ of the test, the carbomer gel dissolved and the particles easily disintegrated. The carmellose gel, on the other hand, did not dissolve throughout the study and blocked the access of dissolution medium to the tested units.

Applesauce was selected for comparison as the most common soft food used for sprinkle formulations. The units dispersed in this medium showed only partial dissolution in a basket apparatus, with high deviation of the results. A basket mesh obstruction by fragments of the food vehicle was observed, and tests in a paddle apparatus were also performed.

In contrast to the basket apparatus, the beads dispersed in applesauce and tested in a paddle apparatus exhibited a fast dissolution that was comparable to the loose units and units dispersed in $0.5 \%$ PAA gel. For pellets or minitablets dispersed in CMC gel, the dissolution was still significantly slower, even when tested in a paddle apparatus. After $30 \mathrm{~min}$, less than $80 \%$ of the declared dose was released (approximately $70 \%$ for pellets and $50 \%$ for minitablets). The structure of $\mathrm{CMC}$ gel was preserved after this time, unlike in PAA gel, which dissolved in $\mathrm{HCl}$ very fast and did not influence the drug release process.

Carbomer gels are prepared via neutralization to $\mathrm{pH} 7.0$ to achieve the maximum viscosity, when the acidic groups in PAA molecules become completely dissociated. Therefore, the acidic groups in carbomer change again into an undissociated form during the dissolution tests in $0.1 \mathrm{M}$ hydrochloric acid, and the gel structure becomes less viscous, which results in the release of API without slowing (25).

Sprinkling the pellets and minitablets with diazepam on a carbomer gel was similar to mixing with a semisolid food, which was demonstrated for the applesauce. However, the use of this standard gel vehicle appeared safer because the composition is simple and reproducible, which allows prediction and avoidance of potential interactions of the active substance with the components of the carrier (26). It is also very likely that the carbomer gel will not affect the drug release in vivo because the same mechanism of viscosity drop in acidic $\mathrm{pH}$ occurs in the stomach.

\section{CONCLUSIONS}

The present study showed how the type of a dispersing vehicle influenced the in vitro properties of a dosage form designed for sprinkling. An alternative method for the determination of the disintegration of pellets and minitablets in liquids, which better correlated with conditions in the mouth compared with a pharmacopoeial test, was introduced. The limitation of this method is the applicability only to low viscosity carriers because problems with the endpoint determination occurred for high viscosity gels. The standard dissolution tests performed for pellets and minitablets dispersed in semisolid vehicles demonstrated the validity of these tests during the development of sprinkle formulation. The results showed that the carbomer gel may be an excellent vehicle for the sprinkles due to the $\mathrm{pH}$-dependent viscosity because the stiff gel structure was not preserved in an acidic $\mathrm{pH}$ (stomach), and the viscosity of the vehicle did not influence the release of diazepam from pellets and minitablets. Furthermore, the use of a paddle apparatus may be recommended for testing these formulations rather than a basket apparatus because more reliable and reproducible results were obtained.

\section{COMPLIANCE WITH ETHICAL STANDARDS}

Conflict of Interest The authors declare that they have no conflicts of interest.

Open Access This article is licensed under a Creative Commons Attribution 4.0 International License, which permits use, sharing, adaptation, distribution and reproduction in any medium or format, as long as you give appropriate credit to the original author(s) and the source, provide a link to the Creative Commons licence, and indicate if changes were made. The images or other third party material in this article are included in the article's Creative Commons licence, unless indicated otherwise in a credit line to the material. If material is not included in the article's Creative Commons licence and your intended use is not permitted by statutory regulation or exceeds the permitted use, you will need to obtain permission directly from the copyright holder. To view a copy of this licence, visit http://creativecommons.org/licenses/by/4.0/.

\section{REFERENCES}

1. Liu F, Ranmal S, Batchelor HK, Orlu-Gul M, Ernest TB, Thomas IW, et al. Patient-centred pharmaceutical design to improve acceptability of medicines: similarities and differences in paediatric and geriatric populations. Drugs. 2014;74(16):1871-89.

2. van Riet-Nales DA, Ferreira JA, Schobben AFAM, de Neef BJ, Egberts TCG, Rademaker CMA. Methods of administering oral formulations and child acceptability. Int J Pharm. 2015;491(12):261-7.

3. Drumond N, van Riet-Nales DA, Karapinar-Çarkit F, Stegemann S. Patients' appropriateness, acceptability, usability and preferences for pharmaceutical preparations: results from a literature review on clinical evidence. Int J Pharm. 2017;521(12):294-305.

4. Cloyd JC, Kriel RL, Jones-Saete CM, Ong BY, Jancik JT, Remmel RP. Comparison of sprinkle versus syrup formulations of valproate for bioavailability, tolerance, and preference. J Pediatr. 1992;120:634-8.

5. Zlotkin S, Antwi KY, Schauer C, Yeung G. Use of microencapsulated iron(II) fumarate sprinkles to prevent recurrence of anaemia in infants and young children at high risk. Bull World Health Organ. 2003;81(2):108-15. 
6. Musiime V, Fillekes Q, Kekitiinwa A, Kendall L, Keishanyu R, Namuddu R, et al. The pharmacokinetics and acceptability of lopinavir/ritonavir minitab sprinkles, tablets, and syrups in african HIV-infected children. J Acquir Immune Defic Syndr. 2014;66(2):148-54.

7. Strickley RG. Pediatric oral formulations: an updated review of commercially available pediatric oral formulations since 2007 . J Pharm Sci. 2019;108(4):1335-65.

8. Lee HS, Lee JJ, Kim MG, Kim KT, Cho CW, Kim DD, et al. Sprinkle formulations - a review of commercially available products. Asian J Pharm Sci. 2019;15:292-310. https://doi.org/ 10.1016/j.ajps.2019.05.003.

9. Trofimiuk M, Wasilewska K, Winnicka K. How to modify drug release in paediatric dosage forms? Novel technologies and modern approaches with regard to children's population. Int J Mol Sci. 2019;20(3200):1-22.

10. FDA. US Department of Health and Human Services. Guidance for industry: size of beads in drug products labeled for sprinkle. 2012.

11. Ranmal SR, Barker SA, Tuleu C. Paediatric solid formulations. In: Bar-Shalom D, Rose K, editors. Pediatric formulations: a roadmap. New York: Springer; 2014. p. 153-70.

12. Kluk A, Sznitowska M, Brandt A, Sznurkowska K, Plata-Nazar $\mathrm{K}$, Mysliwiec M, et al. Can preschool-aged children swallow several minitablets at a time? Results from a clinical pilot study. Int J Pharm. 2015;485(1-2):1-6.

13. FDA. US Department of Health and Human Services. Guidance for industry: use of liquids and/or soft foods as vehicles for drug administration: general considerations for selection and in vitro methods for product quality assessment. 2018.

14. Karkossa F, Krueger A, Urbaniak J, Klein S. Simulating different dosing scenarios for a child-appropriate valproate ER formulation in a new pediatric two-stage dissolution model. AAPS PharmSciTech. 2017;18(2):309-16.

15. FDA. U.S. Department of Health and Human Services. Guidance for industry: food-effect bioavailability and fed bioequivalence studies. 2002.

16. Kersten E, Barry A, Klein S. Physicochemical characterisation of fluids and soft foods frequently mixed with oral drug formulations prior to administration to children. Pharmazie. 2016;71(3):122-7.
17. Jackson S, Naunton M. Optimising medicine administration in patients with swallowing difficulties. Australian Pharm. 2017;1:28-31.

18. Kluk A, Sznitowska M. Application properties of oral gels as media for administration of minitablets and pellets to paediatric patients. Int J Pharm. 2014;460(1-2):228-33.

19. Kaur P, Kim K. Pharmacokinetics and brain uptake of diazepam after intravenous and intranasal administration in rats and rabbits. Int J Pharm. 2008;364(1):27-35.

20. Wilson S, Houpt M. Project usap 2010: use of sedative agents in pediatric dentistry-a 25-year follow-up survey. Pediatr Dent. 2016;38(2):127-33.

21. Roxane Laboratories Inc. Diazepam Intensol Oral Solution The Summary of Product Characteristics. 2012.https:// docs.boehringer-ingelheim.com/Prescribing \%20Information/ PIs/Roxane/Diazepam/Diazepam \%20Oral\%20Solution.pdf. Accessed: 16 April 2020.

22. Abdelbary G, Eouani C, Prinderre P, Joachim J, Reynier J, Piccerelle P. Determination of the in vitro disintegration profile of rapidly disintegrating tablets and correlation with oral disintegration. Int J Pharm. 2005;292(1-2):29-41.

23. Grube A, Gerlitzki C, Brendel M. Dissolution or disintegration - substitution of dissolution by disintegration testing for a fixed dose combination product. Drug Dev Ind Pharm. 2019;45(1):130-8.

24. Lopez FL, Ernest TB, Orlu M, Tuleu C. The effect of administration media on palatability and ease of swallowing of multiparticulate formulations. Int J Pharm. 2018;551(1-2):6775.

25. Bonacucina G, Martelli S, Palmieri GF. Rheological, mucoadhesive and release properties of Carbopol gels in hydrophilic cosolvents. Int J Pharm. 2004;282(1-2):115-30.

26. EMA. Committee for Medicinal Products for Human Use. Guideline on pharmaceutical development of medicines for paediatric use. Vol. 44. 2013.

Publisher's Note Springer Nature remains neutral with regard to jurisdictional claims in published maps and institutional affiliations. 